\title{
Artificial Light at Night Causes Topdown and Bottomup Trophic Effects on Invertebrate Populations
}

Bennie, Jonathan; Davies, Thomas W.; Cruse, David; Inger, Richard; Gaston, Kevin J.

\section{Journal of Applied Ecology}

DOI:

$10.1111 / 1365-2664.13240$

Published: 01/11/2018

Peer reviewed version

Cyswllt i'r cyhoeddiad / Link to publication

Dyfyniad o'r fersiwn a gyhoeddwyd / Citation for published version (APA):

Bennie, J., Davies, T. W., Cruse, D., Inger, R., \& Gaston, K. J. (2018). Artificial Light at Night Causes Topdown and Bottomup Trophic Effects on Invertebrate Populations. Journal of Applied Ecology, 55(6), 2698-2706. https://doi.org/10.1111/1365-2664.13240

Hawliau Cyffredinol / General rights

Copyright and moral rights for the publications made accessible in the public portal are retained by the authors and/or other copyright owners and it is a condition of accessing publications that users recognise and abide by the legal requirements associated with these rights.

- Users may download and print one copy of any publication from the public portal for the purpose of private study or research.

- You may not further distribute the material or use it for any profit-making activity or commercial gain

- You may freely distribute the URL identifying the publication in the public portal ?

Take down policy

If you believe that this document breaches copyright please contact us providing details, and we will remove access to the work immediately and investigate your claim. 


\title{
Journal of Applied Ecology
}

DR JONATHAN JAMES BENNIE (Orcid ID : 0000-0003-4394-2041)

DR THOMAS WYNTER DAVIES (Orcid ID : 0000-0002-4673-9893)

PROFESSOR KEVIN J GASTON (Orcid ID : 0000-0002-7235-7928)

Article type : Research Article

Standard paper

Handling Editor: Owen Lewis

\section{Artificial Light at Night Causes Top-down and Bottom-up Trophic Effects on} Invertebrate Populations

\author{
Running title: Trophic Effects of Artificial Light \\ Jonathan Bennie ${ }^{1,3}$, Thomas W Davies ${ }^{1,2,4}$, David Cruse ${ }^{1,5}$, Richard Inger ${ }^{1,6}$ and Kevin J. Gaston ${ }^{1,7}$ \\ ${ }^{1}$ Environment and Sustainability Institute, University of Exeter, Cornwall Campus, Penryn, Cornwall \\ UK TR10 9FE \\ ${ }^{2}$ School of Ocean Sciences, Bangor University, Menai Bridge, Anglesey UK LL59 5AB
}

This article has been accepted for publication and undergone full peer review but has not been through the copyediting, typesetting, pagination and proofreading process, which may lead to differences between this version and the Version of Record. Please cite this article as doi: $10.1111 / 1365-2664.13240$

This article is protected by copyright. All rights reserved. 
3 email: j.j.bennie@exeter.ac.uk

${ }^{4}$ email: thomas.davies@bangor.ac.uk

${ }^{5}$ email: d.cruse@exeter.ac.uk

${ }^{6}$ email: richinger@gmail.com

${ }^{7}$ email: k.j.gaston@exeter.ac.uk

Corresponding authors: Jonathan Bennie, Thomas Davies or Kevin Gaston (joint corresponding authors), Environment and Sustainability Institute, University of Exeter, Cornwall Campus, Penryn, Cornwall UK TR10 9FE, j.j.bennie@exeter.ac.uk, +44 1326259476

\section{Abstract}

1. Globally, many ecosystems are exposed to artificial light at night. Nighttime lighting has direct biological impacts on species at all trophic levels. However, the effects of artificial light on biotic interactions remain, for the most part, to be determined.

2. We exposed experimental mesocosms containing combinations of grassland plants and invertebrate herbivores and predators to illumination at night over a three-year period to simulate conditions under different common forms of street lighting.

3. We demonstrate both top-down (predation controlled) and bottom-up (resource controlled) impacts of artificial light at night in grassland communities. The impacts on invertebrate herbivore abundance were wavelength dependent and mediated via other trophic levels.

4. White LED lighting decreased the abundance of a generalist herbivore mollusc by $55 \%$ in the presence of a visual predator, but not in its absence, while monochromatic amber light (with a peak wavelength similar to low pressure sodium lighting) decreased abundance of a specialist herbivore

This article is protected by copyright. All rights reserved. 
aphid (by 17\%) by reducing the cover and flower abundance of its main food plant in the system. Artificial white light also significantly increased the food plant's foliar carbon to nitrogen ratio.

5. We conclude that exposure to artificial light at night can trigger ecological effects spanning trophic levels, and that the nature of such impacts depends on the wavelengths emitted by the lighting technology employed.

6. Policy implications. Our results confirm that artificial light at night, at illuminance levels similar to roadside vegetation, can have population effects mediated by both top-down and bottom-up effects on ecosystems. Given the increasing ubiquity of light pollution at night, these impacts may be widespread in the environment. These results underline the importance of minimising ecosystem disruption by reducing light pollution in natural and semi-natural ecosystems.

\section{Keywords}

Light pollution, Photopollution, Grasslands, Trophic levels, Aphids, Molluscs, artificial light, street lights

\section{INTRODUCTION}

Throughout evolutionary time, most terrestrial ecosystems have been exposed to regular daily cycles of sunlight and darkness. Common adaptations to light cycles include endogenous circadian rhythms (McClung 2001; Panda et al., 2002), photoperiodic detection of the seasons (Provencio 2010), partitioning of activity throughout the diel, lunar and annual cycles (Bennie et al., 2014), or adaptation to nocturnal or diurnal activity through specialised sensory systems (Greiner 2006). Light acts as a signal and as a resource, providing energy for photosynthesis, and as a limiting factor for the partitioning of time (Kronfeld-Schor and Dayan 2003). Adaptive responses to the spectral composition of natural light are also widespread, for example in the use of red/far red ratios in

This article is protected by copyright. All rights reserved. 
shade detection in plants (Franklin and Whitelam 2005), and in the detection of water depth due to the attenuation of different wavelengths of light in corals (Mundy and Babcock 1998).

Exposure to artificial light at night has increasingly encroached on the natural environment (Bennie et al., 2015a; Gaston et al., 2015). Lighting not only affects ecosystems in the vicinity of human activity, but illuminated transport networks fragment landscapes, isolating dark patches of habitat (Threlfall et al., 2013), and diffuse light or "skyglow" extends the area exposed to low levels of artificial light for tens to hundreds of kilometres around towns and cities (Kyba et al., 2011; Kyba and Hölker 2013). A wide range of ecological effects of artificial light have been recorded (Gaston et al., 2013). They have the potential to alter population dynamics (Gaston and Bennie 2014), restructure ecological communities (Davies et al., 2012, 2015; Spoelstra et al., 2015; Manfrin et al., 2017), alter species interactions (Macgregor et al., 2014), and change the provision of ecosystem functions and services (Lewanzik and Voigt 2014; Meyer and Sullivan 2013). An estimated 23\% of the land mass experiences nighttime sky brightness at a level that is considered light-polluted (Falchi et al., 2016) with light pollution growing globally at a rate of around 2\% a year (Kyba et al., 2017).

Despite the evidence of profound ecological impacts across different taxonomic groups, and growing evidence that restructuring of ecological communities under artificial light may be widespread, the effect of artificial nighttime light on biotic interactions remains poorly understood. Such effects could be "top down", in which direct effects on predators or foragers have secondary effects on lower trophic levels, or "bottom up", in which direct effects of artificial light on primary producers impact populations at higher trophic levels (Bennie et al., 2015b). Top-down and bottom-up effects may restructure food webs (Rzanny et al., 2013) and anthropogenic pressures may impact both kinds of interactions simultaneously (Van der Putten et al., 2013). Indeed, for drivers of global environmental change such as $\mathrm{CO} 2$ enrichment, nitrogen deposition, climate change, biotic invasions and land use, species interactions frequently mediate the response of ecosystems (Tylianakis et al., 2008). Disentangling direct effects, top-down and bottom-up biotic interactions is therefore critical

This article is protected by copyright. All rights reserved. 
to understanding, and mitigating, the ecosystem-level effects of artificial light at night. In order to disentangle these effects, there is a need for controlled, replicated field experiments in tractable systems.

We present data from an experimental grassland system designed to elucidate top-down and bottom-up effects of artificial light at night. The experiment compared control treatments which experienced natural darkness at night with experimental treatments simulating both low-pressure sodium and white LED street lighting. We monitored the populations of herbivores, and the cover and flowering of plants, to investigate the response of these simple ecosystems to nighttime illumination, and assess whether effects bridge up or down trophic levels. We specifically looked for three forms of response: (i) top down effects, in which we would expect to detect a response to artificial light in herbivores and/or plants in the presence of predators but not in their absence, indicating that the response to light is mediated by predation rate; (ii) bottom-up effects, in which we expect to detect a response to artificial light in herbivores in both the presence and absence of predators, and a corresponding response in plants in the presence and absence of herbivores, indicating that the latter response is mediated by resource availability; and (iii) non-trophic or indeterminate effects, in which we would detect a response in one trophic level only. Here we report combined results for three years of data from the experiment (2013 to 2015), providing evidence for both bottom-up effects of artificial light on a specialist herbivore, mediated by direct effects of artificial light on its food plant, and top-down effects on a generalist herbivore, mediated by direct effects of artificial light on predation rate.

This article is protected by copyright. All rights reserved. 


\section{MATERIALS AND METHODS}

\section{Experimental design}

We established 54 experimental grassland 'mesocosms' outdoors in July 2012 (see supplementary figure S1; Bennie et al. 2015b) in a $35 \mathrm{~m}$ x $35 \mathrm{~m}$ field enclosure at the University of Exeter's Penryn Campus $\left(50^{\circ} 10^{\prime} \mathrm{N}, 5^{\circ} 7^{\prime} \mathrm{W}\right.$, altitude $\left.106 \mathrm{~m}\right)$. Each mesocosm consisted of a $1 \mathrm{~m}$ long, $0.5 \mathrm{~m}$ wide and $0.2 \mathrm{~m}$ deep trough, lined with woven plastic textile for drainage and filled with coarse builder's sand, and mounted on a wooden platform $0.75 \mathrm{~m}$ above the ground. In each mesocosm, 72 individual grassland plants were planted, representing four individuals of each of 18 common grassland species grown in spring from seed gathered locally from wild plants in 2011 . These were selected to be representative of species common in roadside verges in the local area and comprised six grasses (Anthoxanthum odoratum, Agrostis tenuis, Holcus lanatus, Cynosurus cristatus, Dactylis glomerata and Festuca ovina), four legumes (Lotus corniculatus, Lotus pedunculatus, Trifolium dubium and Trifolium pratense), and eight non-leguminous forbs (Leucanthemum vulgare, Achillea millefolium, Leontodon saxatilis, Hypochaeris radicata, Prunella vulgaris, Centaurea nigra, Ranunculus acris and Plantago lanceolata). Seeds were sown in sand in seed trays in a polytunnel during February 2012 and seedlings were transplanted first into modular trays and then planted in a randomized grid pattern $5 \mathrm{~cm}$ apart within the central section of each mesocosm in July 2012. A standard nutrient solution was applied during July 2012 to establish initial plant growth. Each mesocosm was enclosed by a wooden frame $1 \mathrm{~m}$ tall and lined with fine anti-thrip mesh to isolate the plant and invertebrate community. A zip in the mesh provided access for maintenance and measurements. All mesocosms were treated with a biodegradable insecticide (pyrethrin) and molluscicide (ferric phosphate pellets) following initial planting to prevent the accidental introduction of invertebrates with sand or seedlings.

This article is protected by copyright. All rights reserved. 
Three levels of trophic complexity were established in the mesocosms. Eighteen mesocosms contained plants only, 18 (bitrophic treatments) contained both plants and herbivores, and 18 (tritrophic treatments) contained plants, herbivores and predators. The plants-only treatment mesocosms were treated at regular intervals with insecticide and molluscicide to prevent the unintentional establishment of invertebrate populations. Both the bitrophic and tritrophic treatments received phased introductions of 20 individuals each of the pea aphid Acyrthosiphon pisum and 30 individuals of the grey field slug Deroceras reticulatum from May to June 2013. Populations of $A$. pisum persisted throughout the experiment, peaking during summer each year and overwintering as both eggs and adults; populations of $D$. reticulatum persisted until autumn/winter 2014 when numbers declined drastically in all mesocosms and showed no sign of recovery with most searches showing zero monthly counts. A further 30 individuals were introduced from June to September 2015. To avoid any confounding effects of this reintroduction, only data on this species prior to the decline, up to September 2014, are analysed here. A. pisum is a specialist feeder on legumes, and individuals were gathered from wild populations feeding on the leguminous forb Lotus pedunculatus. D. reticulatum is a generalist omnivore, feeding predominantly on the foliage of a wide range of plant species. The tritrophic treatments also received introductions of four adult individuals (one male, three females) of the predatory ground beetle Pterostichus melanarius in August 2013, July 2014 and three individuals (one male, two females) in August 2015, and nine unsexed adult individuals of the ladybird Adalia bipunctata in May 2013, 10 adults in May 2014, and 10 individuals ( 5 adult and 5 final instar larvae) in May 2015. A. bipunctata is a specialist predator of aphids; $P$. melanarius is a generalist predator that will feed on the most available prey, including both slugs and aphids (Pollet and Desender 1987). We found no reference in the literature to $P$. melanarius feeding on A. bipunctata or other ladybird adults or larvae, but this possibility cannot be ruled out. Individuals of $A$. pisum, D. reticulatum and $P$. melanarius were collected from wild populations in grassland in the vicinity of the experimental site; $A$. bipunctata were obtained from a commercial horticultural supplier (Green Gardener, Stokesby, U.K.).

This article is protected by copyright. All rights reserved. 
Two light treatments (white and amber) and unlit controls were allocated to mesocosms in a crossfactorial design with trophic level, with six replicates of each light and trophic treatment combination randomly distributed within a grid pattern (supplementary figure S2). The light treatments each consisted of a strip of light-emitting diodes (LEDs) mounted on a wooden bar across the top of the mesocosm and facing downwards. The 'white' treatment consisted of 'cool white' LEDs, with a spectrum similar to those in commercial LED street lighting systems (see supplementary figure S3). The 'amber' treatment consisted of a virtually monochromatic LED strip with a single narrow peak in the orange portion of the spectrum, around $588 \mathrm{~nm}$, to simulate the peak emittance of monochromatic low-pressure sodium (LPS) lighting at $589.3 \mathrm{~nm}$.

The LED strips were cut to a length so that both lighting treatments provided an illuminance of approximately $10 \mathrm{~lx}$ at the unshaded sand surface and $15 \mathrm{~lx}$ at $20 \mathrm{~cm}$ height. These illuminance levels are within the range of those typical of roadside vegetation under street lights (Bennie et al. 2016). Light treatments were powered by $12 \mathrm{~V}, 125$ Ah vehicle batteries and triggered by lightdetecting photocells mounted on top of the frame, to switch on at sunset (when ambient light levels fell below $70 \mathrm{~lx}$ ) and off at sunrise (above $110 \mathrm{~lx}$ ). Unlit controls reproduced the mounting bar and structure of the lit treatments but had no light source. Nighttime light levels measured within the control mesocosms were comparable to background levels in an adjacent unlit area of the campus, typically around $0.1 \mathrm{~lx}$ at full moon and $0.01 \mathrm{~lx}$ at new moon. Illuminance measurements were taken with a photoradiometer calibrated to a CIE curve (HD2102.2, Delta Ohm, Caselle di Selvazzano, Italy).

\section{Vegetation sampling}

Plant cover for each species was measured in July of each year using a $30 \mathrm{~cm}$ long point-quadrat frame (Sutherland 2000 ) with seven pins at $5 \mathrm{~cm}$ spacing. The frame was placed along five transects at $10 \mathrm{~cm}$ spacing across the central section of the mesocosm, to form a $30 \times 40 \mathrm{~cm}$ grid of 35 pin

This article is protected by copyright. All rights reserved. 
drops (pin diameter $5 \mathrm{~mm}$ ) covering the central planted area of the mesocosm. The number of pin drops that made contact with each species was recorded.

The abundance of flowers of Lotus pedunculatus, the dominant leguminous forb, was analysed due to the importance of the flowers as a seasonal food source for the aphid A. pisum in the system. The abundance of flowers was recorded in each of the 54 mesocosms every two weeks from April to September of each year. The number of mature, but not yet senescent, inflorescences were counted on each occasion. In order to estimate the total resource available to the aphid across the season, we pooled all data from surveys during June, July and August of each year and analysed the total number of flowers.

In June 2015, leaf samples were collected from L. pedunculatus to measure the carbon to nitrogen $(\mathrm{C} / \mathrm{N})$ ratio of the leaves of this species. Leaves from the tips of four growing shoots of the species were collected, where possible from four separate plants, before being freeze-dried, combined into a single sample per mesocosm and homogenised. Dry samples were analysed immediately in a SerCon Callisto CF_IRMS 20-22 Mass Spectrometer. Total carbon and nitrogen contents were measured and the $\mathrm{C} / \mathrm{N}$ ratio calculated.

\section{Invertebrate sampling}

The abundance of $A$. pisum was assessed every two weeks from April to September in each year, by a single observer using a three-minute timed count in each mesocosm. During the three minutes, the vegetation was thoroughly and systematically searched by hand and all aphids observed were counted.

The abundance of $D$. reticulatum was assessed by a monthly 5 minute timed count by multiple observers by torchlight in the evening at least 30 minutes after sunset, when the species was active. Treatment lights were switched off before sunset on the nights of surveys to avoid the confounding

This article is protected by copyright. All rights reserved. 
effects of light on activity, or differences in detection rates under different light conditions. During counting, recorded individuals of $D$. reticulatum were temporarily removed from the mesocosm to avoid multiple counts of the same individual. For both herbivore species, the duration of timed searches was chosen to maximise information from a reasonable sampling effort. The search times were imposed as early trials showed that the rate of discovery of new individuals decreased rapidly when the duration of searches were extended further. A fixed-duration survey standardised search effort, limited the time during which the mesocosm was open, and in the case of $A$. pisum, avoided the risk of accidentally double-counting individuals.

Due to the complexity of the vegetation, and the difficulty of searching the substrate without damaging the plants, it was not possible to assess predator abundance systematically within this system after their introduction. However, individuals of both predator species were observed in the majority of tritrophic treatments throughout the summer months, so we conclude that populations persisted throughout the breeding season. Fresh adult $P$. melanarius were observed in spring 2014, suggesting that breeding of this species took place (supplementary table S1). No larvae of either species were observed, and there was no evidence that $A$. bipunctata successfully bred or overwintered within the mesocosms.

\section{Data analyses}

Vegetation cover data were analysed using a generalised linear mixed model with a binomial error structure, fitted using penalised maximum likelihood estimation with the gamlss package (Rigby and Stasinopoulos 2005) in R v 3.0.1 (R Core Team 2013). Each functional group (grasses, legumes and non-leguminous forbs) was analysed separately, with year (YEAR, coded as a categorical variable), light treatment (LIGHT; coded as control, amber or white), the presence of herbivores (HERB; coded as presence/absence), and the presence of predators (PRED, coded as presence/absence) as 
predictor variables, as well as the interaction terms YEAR:LIGHT, YEAR:HERB YEAR:PRED, YEAR:LIGHT:HERB and YEAR:LIGHT:PRED. Mesocosm identity (PLOT) was included as a random variable (with random intercept and slope with respect to YEAR), to allow for repeated measures of the same mesocosm in different years. A full list of cover values for each species is presented in the supplementary material (table S2).

Flowering data for Lotus pedunculatus were analysed using a generalised linear mixed model with a negative binomial error structure, fitted using penalised maximum likelihood estimation in the gamlss package. Since the availability of inflorescences over the whole season was of interest, the total number of mature inflorescences for June, July and August of each year was aggregated into annual totals, and modelled as above with YEAR (coded as a categorical variable), interactions with year and light treatment (YEAR:LIGHT), the presence of herbivores (YEAR:HERB), and the presence of predators (YEAR:PRED), and three-way interactions (YEAR:HERB:LIGHT and YEAR:PRED:LIGHT) as fixed factors and mesocosm identity (PLOT) as a random factor, to control for repeated measures.

Since measurements of $L$. pedunculatus foliar C/N ratios were available for just one year (2015), these were analysed for effects of light using a generalised linear model in which $\mathrm{C} / \mathrm{N}$ ratio was modelled with light treatment, presence of herbivores and presence of predators, and their interactions as fixed factors (LIGHT, HERB, PRED, LIGHT:HERB and LIGHT:PRED).

In all analyses of vegetation, flowering and $\mathrm{C} / \mathrm{N}$ ratios the full model was tested for statistical significance against a null model (effect of year and random term only) using a chi-square test (Pinheiro and Bates 2009); interaction terms were replaced by simple terms for the treatment, or dropped altogether, if the resulting model had a lower AIC value. The appropriateness of the choice of link function was confirmed by visual assessment of quantile ( $Q-Q)$ plots of the model residuals and predicted values.

This article is protected by copyright. All rights reserved. 
Aphid and slug counts were analysed using a generalised linear mixed model with a zero-inflated negative binomial error structure fitted using the gamlss package. In these analyses, monthly, rather than annual counts were modelled as a function of DATE (as a categorical variable with a unique value for each monthly time point), LIGHT (control, amber or white), and PRED (presence or absence of predators), as well as interactions between DATE, LIGHT and PRED, as fixed factors, and with mesocosm identity (PLOT) as a random factor. Interaction terms between DATE and other fixed factors were dropped from the model if they did not decrease AIC values, but interactions between LIGHT and PRED were retained, in order to test whether effects of the light treatment were mediated by the presence or absence of predators. Normality of the residuals was confirmed by visual assessment of quantile ( $Q-Q)$ plots of the model residuals and predicted values.

\section{RESULTS}

\section{Effects of light, herbivory and predation on vegetation cover}

The most parsimonious model for the cover of grasses did not include any effects of light or trophic level, but showed significant differences between years $\left(R^{2}=0.75, p<0.001\right)$. The most parsimonious model for leguminous forbs $\left(R^{2}=0.71\right)$ included effects of year, light and trophic treatments, as well as two-way interactions between year and both light treatment and trophic treatments. There was a $27 \%$ decrease in cover in the presence of herbivores only (effect of herbivores significant at $p<0.001)$, but only a $14 \%$ decrease when both herbivores and predators were present (effect of predators significant at $p=0.016$ ) across all years. In 2015 , there was a $19 \%$ decrease in legume cover under amber lights and $12 \%$ decrease in under white lights (significant at $p$ $=0.032$ and $p=0.040$ respectively). For non-leguminous forbs, the most parsimonious model included effects of year, light and trophic treatments, but no interaction terms. There was a $16 \%$ increase in cover in the presence of herbivores only (effect of herbivores significant at $p<0.001$ ) and

This article is protected by copyright. All rights reserved. 
a $10 \%$ increase in cover in the presence of herbivores and predators (effect of predators significant at $p=0.017$ ). No significant effects of light treatment were detected on the cover of grasses or nonleguminous forbs. No interactions between light and herbivory or predation were found to be significant. The models selected are shown in supplementary table $\mathrm{S} 3$, and terms and properties of the most parsimonious model are shown in supplementary table $\mathrm{S} 4$.

\section{Effects of light, herbivory and predation on flowering and $\mathrm{C} / \mathrm{N}$ ratios of $L$. pedunculatus}

There were significant effects of both artificial light and herbivory on the number of inflorescences produced by L. pedunculatus (Figure 1b). Under both amber and white nighttime light, this species produced significantly fewer flower heads in all years (49\% fewer at $p<0.001$ and $29 \%$ fewer at $p=$ 0.0176 respectively); there were also significantly fewer inflorescences observed in the presence of herbivores $(45 \%$ fewer at $p<0.001)$. The model had an $R^{2}$ value of 0.39 . No significant effects of the presence of predators on inflorescence count were found, nor were there significant interactions between trophic treatment and light treatment. Model selection and terms and properties of the model are shown in supplementary tables S5 and S6.

There was a significant effect of artificial white light on C/N ratios in L. pedunculatus leaves in 2015 $(P=0.0045) ; C / N$ ratios were decreased by $29.5 \%$ on average compared to controls. Model selection and terms and properties of the model are shown in supplementary tables S7 and S8.

\section{Effects of light and predators on $A$. pisum abundance}

The most parsimonious model for $A$. pisum abundance did not include interaction terms between date and light treatment or date and predation. Across all years, the abundance of A. pisum was $17 \%$ lower under the amber nighttime light treatment (Figure $2 \mathrm{a}, p=0.002$ ). No significant effects of white light, predation or interactions were found. The alternative model forms and terms and 
properties of the most parsimonious model are shown in supplementary tables S9 and S10; monthly counts are shown in supplementary figure S4.

\section{Effects of light and predators on $D$. reticulatum abundance}

The abundance of $D$. reticulatum was significantly decreased (by $55 \%$ ) under the combination of white nighttime light and predation (Figure $2 b ; p=0.026$ ); the negative effect of predation alone was not significant at the $95 \%$ confidence level $(P=0.13)$, nor was any significant effect of white light detected in the absence of predators. Again, including interaction effects for individual months of data did not improve the parsimony of the model as judged by AIC values. The alternative model forms and terms and properties of the most parsimonious model are shown in supplementary tables S11 and S12; monthly counts are shown in supplementary figure S5.

\section{DISCUSSION}

There is an increasing awareness of ecological light pollution as an important environmental issue, and recognition both of the extent to which natural and semi-natural ecosystems are exposed to anthropogenic light at night (Bennie et al. 2015a, Gaston et al., 2015) and of the value of habitats that have now come to be frequently illuminated, such as roadside verges and hedgerows (Hovd and Skogen 2005; Cousins 2006; Hanley and Wilkins 2015), domestic gardens (Davies et al., 2009; Goddard et al., 2010) and urban ecosystems (Angold et al., 2006; Gaston et al., 2013; Stott et al., 2015) for biodiversity conservation and the maintenance of ecosystem services.

This study demonstrates that continuous artificial light at night equivalent to that recorded in roadside vegetation under street lighting, can cause population-level effects on plants and invertebrates, that these effects can be mediated by both top-down and bottom-up processes, and that the nature of these effects depends on the lighting technology employed.

This article is protected by copyright. All rights reserved. 
Exposure to white LED light significantly reduced numbers of the generalist herbivore $D$. reticulatum in the presence of predators, but not in their absence (Figure 2b). We conclude that predation rates by $P$. melanarius were higher under the white nighttime light, driving a top-down effect on $D$. reticulatum abundance. $P$. melanarius is a nocturnal predator that locates its prey by sight and olfactory cues, and broad spectrum light may therefore aid its prey location and/or increase its activity; Allema et al. (2012) found variation in activity levels in this species under different wavelengths of light, with both males and females spending less time moving under high-pressure sodium lighting than under red LEDs. While the spectra of these lights are not comparable with the present study, it is clear that activity patterns in this species are sensitive to different wavelengths of artificial light.

Pitfall trap catches of some predatory invertebrates including carabid beetles are known to be higher under street lights in road verges (Davies et al., 2012), although Manfrin et al., (2017) found reduced trap rates of carabid species under high-pressure sodium lighting. Other predator species aggregate around artificial light, utilising it to hunt at night, including reptiles (Garber 1978), bats (Blake et al., 1994), birds (Negro et al., 2000), spiders (Frank 2009) and fish (Becker et al., 2012), but determining the impact of increased predation rates on prey populations is challenging. Our results show that light at night can decrease prey species abundance through increasing predator density, activity, or efficiency, highlighting the potential for far reaching impacts on predator-prey dynamics.

Exposure to amber light significantly decreased the abundance of the specialist herbivore $A$. pisum both in the presence and absence of predators (Figure 2a). We have previously shown that $A$. pisum populations declined more rapidly in amber light treatments in late summer than they did in dark or white-lit treatments (Bennie et al., 2015b); the results of the present study show that the pattern was maintained over three years and is likely driven by resource availability. We base this conclusion on the significant effect of artificial light on leguminous plants in this system, regardless of whether herbivores were present or absent. Three measures of legume resource availability and 
quality for aphids were reduced under artificial light treatments. Total legume cover was reduced under amber and white light by 2015, the final year of this study. Inflorescence abundance of $L$. pedunculatus was reduced under both amber and white light. The $\mathrm{C} / \mathrm{N}$ ratio of the main food plant of $A$. pisum, inversely related to forage quality (Bezemer and Jones 1998), was significantly higher under white lights when measured in 2015.

While there is evidence that photoperiod may have a direct effect on aphid reproduction (Erlykova 2003), Sanders et al. (2015) found that white LED nighttime lighting reduced abundance of two aphid species, including A. pisum established on an experimental monoculture of beans Vicia faba, associated with a decrease in biomass of their food resource. In the current study there is strong evidence that artificial light decreased the abundance of food for this species. Artificial light had a detectable effect on the composition of plant species within the mesocosms, decreasing the cover of legumes compared to other functional types in the third year of the study, and decreasing the number of flowers of the most abundant legume L. pedunculatus in all three years. The more pronounced effect of the amber, rather than white, treatment is consistent with previous observations (Cathey and Campbell 1975) that incandescent and sodium light sources are more effective in producing vegetative and flowering responses in plants than other sources (Briggs 2006; Bennie 2016).

There has been a global shift away from gas-discharge lamps, including sodium lights, towards solid state LED lighting, with the aim of decreased energy consumption, although it has been argued that efficiency gains lead to a compensatory increase in lighting use, offsetting energy savings (Kyba et al., 2017). In principle, LED technology could allow greater flexibility in the wavelengths of light emitted; however in practice the vast majority of outdoor "white" LED lighting currently installed is based on blue LEDs with a yellow phosphor coating producing a blue-rich white light. This shift towards exposure to short-wavelength light has caused concern for human health (West et al., 2011) and ecological systems (Davies et al., 2017). Known ecological responses to light at night vary in 
their sensitivity to different wavelengths, although many responses appear to be more sensitive to "blue" light (Longcore et al., 2018). Our results suggest that the response of an ecosystem to changes in the intensity and spectra of artificial light in the environment may be complex and mediated through multiple physiological pathways and trophic levels.

The implications of such findings for planning ecologically sensitive outdoor lighting are important. While much is still unknown about the ecological consequences of artificial light at night, we propose three principles for lighting design based on the evidence to date. First, the precautionary step of avoiding any illumination around natural and semi-natural ecosystems should be taken. Particular care should be taken around the habitats of species for which there is strong evidence of direct harmful effects of artificial light, but the ecosystem-level impacts are likely to be far wider than the small group of species for which the direct effects of light are well known. Second, where illuminating the environment is deemed necessary due to overriding concerns of public amenity or safety, lighting should be limited to the time, intensity and place at which it is required (Gaston et al., 2012). Here, the flexibility of solid state lighting technology in terms of enhanced directionality, dimming and rapid "warm up" times probably offers untapped potential, as do "smart" lighting technologies that can respond to changing local pedestrian or traffic activity levels. Third, the ecological impacts of artificial light may be reduced by controlling the emission spectra and/or lighting technology employed in different situations, but there may not be a single most "environmentally sensitive" lighting technology. Our results suggest that great care should be taken to consider both the physiological and ecological pathways through which the impacts of artificial light are realised. Plants, and hence specialist herbivores, are likely to be susceptible to higher wavelength light, particularly the red/far red ratio (Cathey and Campbell 1975; Briggs 2006; Bennie et al., 2016), while many physiological pathways such as cryptochrome and melatonin, and behaviours such as insect phototaxis are most sensitive to lower-wavelength blue light (Longcore et al., 2018). Species that are able to utilise artificial light for vision, are likely to respond to broad wavelength "white" light. While ecological light pollution is a global phenomena, the range of 
impacts, and the most effective mitigation strategies, may vary with the species composition and structure of the local ecosystem. In each case, an assessment not only of the responses of individual species within an ecosystem but also how these impacts may cascade through trophic levels is critical if we are to manage and mitigate the ecological impacts of artificial light at night.

\section{AUTHORS' CONTRIBUTIONS}

KG conceived the idea for this study and secured funding, KG, JB, TD and DC designed the experiment. DC, JB and TD built and maintained the experiment and collected data. JB, TD and RI analysed the data, JB wrote the initial manuscript and all authors contributed to subsequent revisions. All authors gave final approval for publication.

\section{ACKNOWLEDGEMENTS}

The research leading to this paper was funded by the European Research Council under the European Union's Seventh Framework programme (FP7/2007-2013)/ERC grant agreement no. 268504 to KJG.

\section{DATA ACCESSIBILITY}

Data available via the Dryad Digital Repository doi:10.5061/dryad.8217n76 (Bennie et al., 2018).

\section{REFERENCES}

Allema AB, Rossing WAH, van der Werf W, Heusinkveld BG, Bukovinszky T, Steingröver E. et al., (2012) Effect of light quality on movement of Pterostichus melanarius (Coleoptera: Carabidae). Journal of Applied Entomology 136, 793-800.

This article is protected by copyright. All rights reserved. 
Angold PG, Sadler JP, Hill MO Pullin A. (2006) Biodiversity in urban habitat patches. Science of the Total Environment 360, 196-204.

Becker A, Whitfield AK, Cowley PD, Järnegren J, Næsje F. (2012) Potential effects of artificial light associated with anthropogenic infrastructure on the abundance and foraging behaviour of estuary-associated fishes. Journal of Applied Ecology 50, 43-50.

Bennie J, Davies TW, Cruse D, Inger R, Gaston KJ. (2018) Data from: Artificial Light at Night Causes Top-down and Bottom-up Trophic Effects on Invertebrate Populations. Dryad Digital Repository DOI: 10.5061/dryad.8217n76

Bennie J, Davies TW, Cruse D, Gaston KJ. (2016) Ecological effects of artificial light at night on wild plants. Journal of Ecology 104, 611-620

Bennie J, Duffy JP, Davies TW, Correa-Cano ME, Gaston KJ (2015a) Global trends in exposure to light pollution in natural terrestrial ecosystems. Remote Sensing 7, 2715-2730

Bennie J, Davies TW, Cruse D, Inger R, Gaston KJ. (2015b) Cascading effects of artificial light at night: resource mediated control of herbivores in a grassland system. Philosophical Transactions of the Royal Society B 370: 20140131

Bennie J, Duffy JP, Inger R, Gaston KJ. (2014) The biogeography of time partitioning in mammals. Proceedings of the National Academy of Sciences USA 2014 111, 13727-13732.

Bezemer TM, Jones TH (1998) Plant-insect herbivore interactions in elevated atmospheric $\mathrm{CO}_{2}$ : quantitative analyses and guild effects. Oikos 82 212-222

Blake D, Hutson AM, Racey PA, Rydell J, Speakman JR. (1994) Use of lamplit roads by foraging bats in southern England. Journal of Zoology 234, 453-462.

This article is protected by copyright. All rights reserved. 
Briggs WR. (2006) Physiology of plant responses to artificial lighting. In: Rich L, Longcore T, editors. Ecological Consequences of Artificial Night Lighting; Island Press: Washington. pp 389411.

Cathey AR, Campbell LE. (1975) Effectiveness of five vision-lighting sources on photo-regulation of 22 species of ornamental plants. Journal of the American Society of Horticultural Science 100, $65-71$.

Cousins SAO. (2006) Plant species richness in midfield islets and road verges - the effect of landscape fragmentation. Biological Conservation 127, 500-509.

Davies TW, Bennie J, Gaston KJ. (2012) Street lighting changes the composition of invertebrate communities. Biology Letters 8, 764-67.

Davies TW, Coleman M, Griffith KM, Jenkins SR. (2015) Night-time lighting alters the composition of marine epifaunal communities. Biology Letters 11, 20150080.

Davies TW, Bennie J, Cruse D, Blumgart D, Inger R, Gaston KJ (2017) Multiple night-time lightemitting diode lighting strategies impact grassland invertebrate assemblages. Global Change Biology 23 2641-2648.

Davies ZG, Fuller RA, Loram A, Irvine KN, Sims V, Gaston KJ. (2009) A national scale inventory of resource provision for biodiversity within domestic gardens. Biological Conservation 142, 761771.

Erlykova N. (2003) Inter- and intraclonal variability in the photoperiodic response and fecundity in the pea aphid Acyrthosiphon pisum (Hemiptera: Aphididae). European Journal of Entomology $100,31-37$.

This article is protected by copyright. All rights reserved. 
Falchi F, Cinzano P, Duriscoe D, Kyba CCM, Elvidge CD, Baugh K, Portnov BA, Rybnikova NA Furgoni R (2016) The new world atlas of artificial night sky brightness. Science Advances 2, e1600377

Frank KD. (2009) Exploitation of artificial light at night by a jumping spider. Peckhamia, 78, 1-3.

Franklin KA, Whitelam GC. (2005) Phytochromes and shade-avoidance responses in plants Annals of Botany 96, 169-175.

Garber SD. (1978) Opportunistic feeding behaviour of Anolis cristatellus (Iguanidae: Reptilia) in Puerto Rico. Transactions of the Kansas Academy of Sciences 811, 79-80.

Gaston, KJ, Davies, TW, Bennie, J Hopkins, J (2012) Reducing the ecological consequences of night-time light pollution: Options and developments. Journal of Applied Ecology, 49, 1256-1266

Gaston KJ, Ávila-Jiménez ML, Edmondson JL. (2013) Managing urban ecosystems for goods and services. Journal of Applied Ecology 50, 830-840.

Gaston KJ, Bennie J, Duffy JP. (2015) Quantifying the erosion of natural darkness in the global protected area system. Conservation Biology 29, 1132-41.

Gaston KJ, Bennie J. (2014) Demographic effects of artificial nighttime lighting on animal populations. Environmental Reviews 22, 323-330.

Gaston KJ, Bennie J, Davies TW, Hopkins J (2013) The ecological impacts of nighttime light pollution: a mechanistic appraisal. Biology Reviews $88,912-27$

Goddard MA, Dougill AJ, Benton TG. (2010) Scaling up from gardens: biodiversity conservation in urban environments. Trends in Ecology and Evolution 25, 90-98.

Greiner B. (2006) Adaptations for nocturnal vision in insect apposition eyes. International Journal of Cytology 250, 1-46.

This article is protected by copyright. All rights reserved. 
Hanley ME, Wilkins JP. (2015) On the verge? Preferential use of road-facing hedgerow margins by bumblebees in agro-ecosystems. Journal of Insect Conservation 19, 67-74.

Hovd H, Skogen A. (2005) Plant species in arable field margins and road verges of central Norway. Agriculture, Ecosystems and Environment 110, 257-265.

Kronfeld-Schor N, Dayan T. (2003) Partitioning of time as an ecological resource. Annual Review of Ecology, Evolution and Systematics 34, 153-181

Kyba CCM, Hölker F. (2013) Do artificially illuminated skies affect biodiversity in nocturnal landscapes? Landscape Ecology, 28, 1637-1640.

Kyba CCM, Ruhtz T, Fischer J, Hölker F. (2011) Cloud Coverage Acts as an Amplifier for Ecological Light Pollution in Urban Ecosystems. PLoS ONE, 6, e17307.

Kyba CCM, Kuester T, Sánchez de Miguel A, Baugh K, Jechow A, Hölker F, Bennie J, Elvidge CD, Gaston KJ, Guanter L (2017) Artifically lit surface of Earth at night increasing in radiance and extent. Science Advances 3, e1701528

Lewanzik D, Voigt CC. (2014) Artificial light puts ecosystem services of frugivorous bats at risk. Journal of Applied Ecology 52, 388-394.

Longcore T, Rodriguez A, Witherington B, Penniman JF, Herf L, Herf M (2018) Rapid assessment of lamp spectrum to quantify ecological effects of light at night. Journal of Experimental Zoology A: Ecological and Integrative Physiology doi.org/10.1002/jez.2184.

Lorne JK, Salmon M. (2007) Effects of exposure to artificial lighting on orientation of hatchling sea turtles on the beach and in the ocean. Endangered Species Research 3, 23-30.

Macgregor C, Pocock MJO, Fox R, Evans DM. (2014) Pollination by nocturnal Lepidoptera, and the effects of light pollution: a review. Ecological Entomology 40, 187-198.

This article is protected by copyright. All rights reserved. 
Manfrin A, Singer G, Larsen S, Weiß N, van Grunsven RHA, Weiß N-S, Wohlfahrt S, Monaghan MT, Hölker F (2017) Artificial light at night affects organism flux across ecosystem boundaries and drives community structure in the recipient ecosystem. Frontiers in Environmental Science 5 61

McClung CR. (2001) Circadian rhythms in plants. Annual Review of Plant Physiology and Plant Molecular Biology 52, 139-162

Meyer LA and Sullivan SMP (2013) Bright lights, big city: influences of ecological light pollution on reciprocal stream-riparian invertebrate fluxes. Ecological Applications 23 1322-1330

Mundy C, Babcock RC (1998) Role of light intensity and spectral quality in coral settlement: implications for depth dependent settlement? Journal of Experimental Marine Biology and Ecology 223, 235-255.

Negro JJ, Bustamante J, Melguizo C, Ruiz JL, Grande JM. (2000) Nocturnal activity of lesser kestrels under artificial lighting conditions in Seville, Spain. Journal of Raptor Research 34, 327329.

Panda S, Hogenesch JB, Kay SA. (2002) Circadian rhythms from flies to human. Nature 16, 329325

Pinheiro JC, Bates DM (2009) Mixed-effects models in S and S-Plus; Springer-Verlag New York.

Pollet M, Desender K. (1987) Feeding ecology of grassland inhabiting carabid beetles (Coleoptera, Carabidae) in relation to the availability of some prey groups. Acta Phytopatholica et Entomologica Hungarica 22, 223-246.

Provencio I. (2010) Shedding light on photoperiodism. Proceedings of the National Academy of Sciences USA 107, 15662-15663

This article is protected by copyright. All rights reserved. 
R Core Team. (2013) R: A language and environment for statistical computing. R Foundation for Statistical Computing, Vienna, Austria. Available: http://www.R-project.org/

Rigby RA, Stasinopoulos DM. (2005) Generalized additive models for location, scale and shape (with discussion), Applied Statistics 54, 507-554.

Rydell J. (2006) Bats and their insect prey at streetlights. In: Rich L, Longcore T, editors. Ecological Consequences of Artificial Night Lighting; Island Press: Washington. pp. 43-60.

Rydell J. (1991) Seasonal use of illuminated areas by foraging northern bats Eptesicus nilssoni. Holarctic Ecology, 14, 203-207.

Rzanny M, Kuu A, Voigt W. (2013) Bottom-up and top-down forces structuring consumer communities in an experimental grassland. Oikos 122, 967-976.

Sanders D, Kehoe R, Tiley K, Bennie J, Cruse D, Davies TW, et al. (2015) Artificial nighttime light changes aphid-parasitoid population dynamics. Scientific Reports 5, 15232.

Spoelstra K, van Grunsven RHA, Donners M, Gienapp P, Huigens ME, Slaterus R, Berendse F, Visser ME, Veenendaal E (2015) Experimental illumination of natural habitat - an experimental set-up to assess the direct and indirect ecological consequences of artificial light of different spectral composition. Philosophical Transactions of the Royal Society B 37020140129

Stott I, Soga M, Inger R, Gaston KJ. (2015) Land sparing is crucial for urban ecosystem services. Frontiers in Ecology and the Environment, 13, 387-393.

Bullock J (2000) Plants. In Sutherland WJ (ed.) Ecological Census Techniques: a handbook. Cambridge University Press, Cambridge.

Threlfall CG, Law B, Banks PB. (2013) The urban matrix and artificial light restricts the nightly ranging behaviour of Gould's long-eared bat (Nyctophilus gouldi) Austral Ecology 38, 921-930.

This article is protected by copyright. All rights reserved. 
Tikka PM, Högmander H, Koski PS. (2001) Road and railway verges serve as dispersal corridors for grassland plants. Landscape Ecology 167, 659-666.

Tylianakis JM, Didham RK, Bascompte J Eardle DA (2008) Global change and species interactions in terrestrial ecosystems. Ecology Letters 11 1351-1363.

Van der Putten WH, Ruiter PC, Bezemer TM, Harvey JA, Wassen M, Wolters V. (2004) Trophic interactions in a changing world. Basic and Applied Ecology 5, 487-494.

West KE, Jablonski MR, Warfield B, Cecil KS, James M, Ayers MA, Maida J, Bowen C, Sliney DH, Rollag MD, Hanifin JP, Brainard GC (2011) Blue light from light-emitting diodes elicits a dosedependent suppression of melatonin in humans. Journal of Applied Physiology 110 619-626.
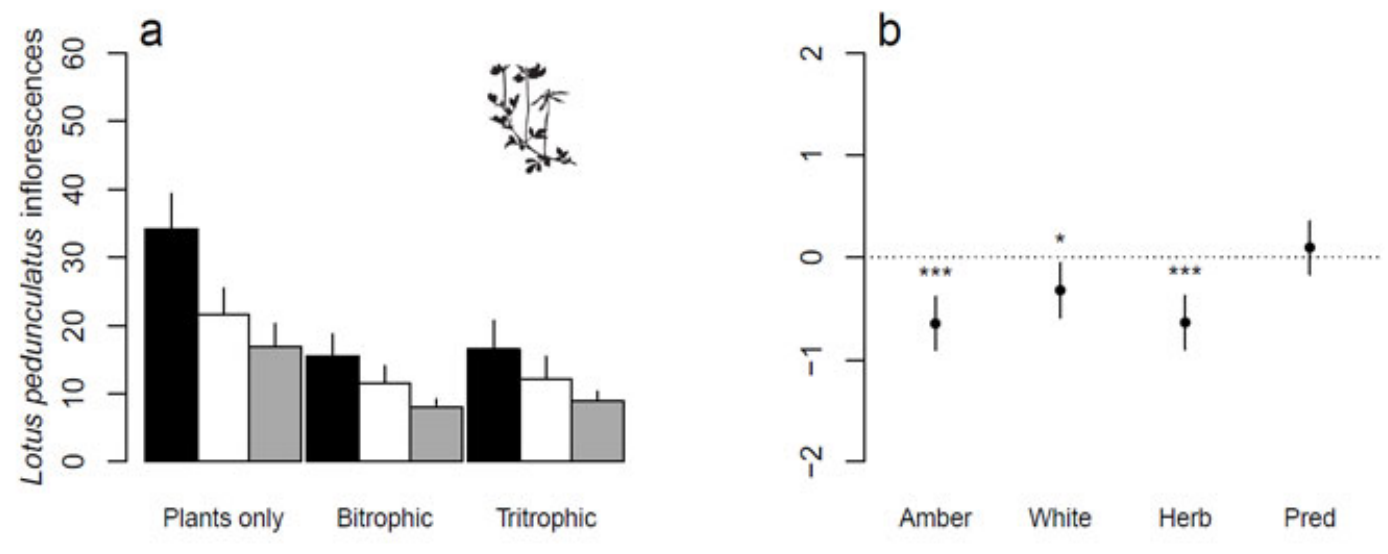

Fig. 1 Counts of Lotus pedunculatus inflorescences in mesocosms. (a) mean annual numbers of flower heads recorded over all bi-weekly counts during summer (from June to August) during 2013 to 2015. Black bars are unlit, white bars represent the white light treatment and dark grey Amber treatment. Vertical lines represent standard deviations, $n=6$ in each case. (b) Effect sizes of artificial This article is protected by copyright. All rights reserved. 
light treatments (Amber and White) and the presence of herbivores (Herb) and predators (Pred) on L. pedunculatus flower counts 2013-2015. Points indicate parameter estimates, associated lines indicate $95 \%$ confidence intervals, and stars indicate effects significantly differing from zero (* $P<0.05, * * P<0.01, * * * P<0.001)$
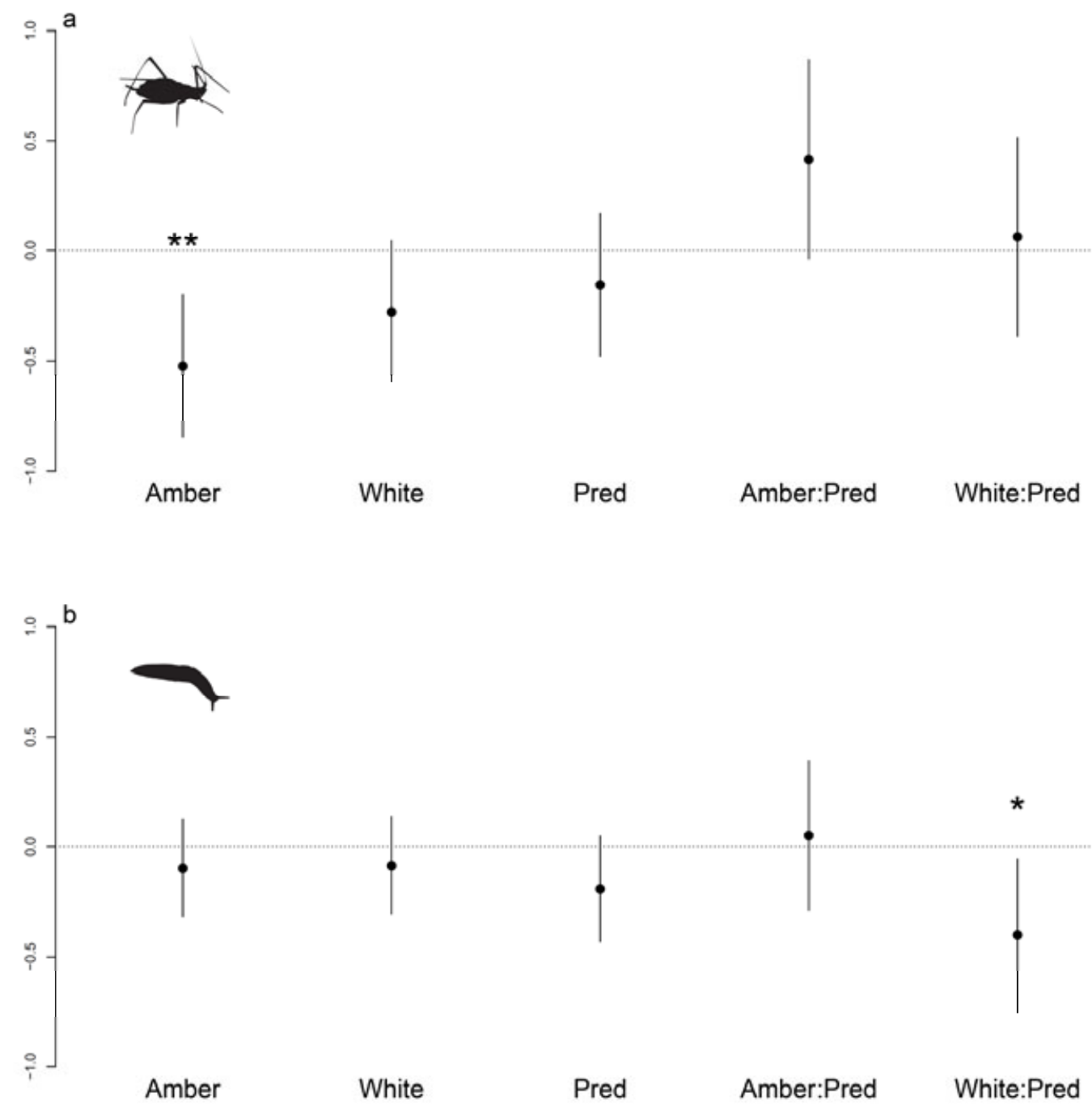

Fig. 2 Effect sizes of artificial light treatments (Amber and White) and the presence of predators (Pred) on (a) Acyrthosiphon pisum and (b) Deroceras reticulatum abundance.. Points indicate parameter estimates, associated lines indicate $95 \%$ confidence intervals, and stars indicate estimates significantly differing from zero $(* \mathrm{P}<0.05, * * \mathrm{P}<0.01, * * * \mathrm{P}<0.001)$.

This article is protected by copyright. All rights reserved. 